\title{
Effect of Simulated Radiation on Sethoxydim Performance Used with and without Vegetable Oils
}

\author{
Hossein HAMMAMI ${ }^{1 *}$, Mohammad Hassan RASHED MOHASSEL ${ }^{1}$, Mehdi PARSA, \\ Mohammad BANNAYAN-AVAL ${ }^{1}$, EskandarZAND ${ }^{2}$ \\ IDepartment of Agronomy, College of Agriculture, Ferdowsi University of Mashhad, Mashhad, Iran; homamihossein@gmail.com ("correspondingauthor) \\ ${ }^{2}$ Department of Weed Research, Plant Protection Research Institute, Tehran, Iran
}

\begin{abstract}
The photodecomposition of post emergence herbicides on leaf surface can be affected via adding vegetable oils to spray tank. Nine vegetable oils were compared to assess the photodecomposition of sethoxydim on wild oat leaf surface under simulated light conditions. The experiment was conducted as completely randomized factorial design with three replications at the College of Agriculture, Ferdowsi University of Mashhad, Iran, in 2013. Each herbicidal solution (with and without vegetable oil) was exposed to simulated light at 0, 5, 10, 20, 30, 60, 120 and 240 MAS (min after spray), for 30 min. The performance of sethoxydim in the presence of turnip, olive, soybean, corn, sunflower, canola, sesame, castor and cotton seed oils, compared to non-vegetable oil solution, increased up to 4.02-, 3.44-, 3.22-, 3.08-, 2.86-, 2.09-, 1.96-, 1.77- and 1.25- fold. All vegetable oils significantly improved the resistance of sethoxydim to light treatment. The effect of vegetable oils on the resistance to photodecomposition of sethoxydim was significant different at less than 60 MAS, while no significant differences were noted among vegetable oils when light treatment occurred at 120 and 240 MAS. Data from the light treatments have confirmed that when vegetable oils were added to sethoxydim, light adverse effect was lower, which is presumably due to disturbance of the cuticule and the rapid absorption of sethoxydim by wild oat leaves. Vegetable oils fatty acids composition effect the resistance to photodecomposition of sethoxydim, as with increasing the unsaturated fatty acid values, the resistance to photodecomposition was improved.
\end{abstract}

Keywords: cuticule, fatty acid, photodecomposition, simulated light, wild oat

Abbreviations: ED-effective dose; MAS-min after spraying; RP-relative potency

\section{Introduction}

Decomposition processes of herbicide include abiotic oxidation and reduction, hydrolysis, biodegradation and photolysis (Schnoor, 1991). One of the most significant decomposition pathways after spraying is photodecomposition. Herbicide photodecomposition is a chemical reaction in which an herbicide compound is broken down by photons and it is not limited to visible light. Any photon with sufficient energy can affect the chemical bonds of a solutions' compound. It may occur in surface waters, in soil, in the atmosphere and on the leaf surface. Ultraviolet radiation (UV) reaching the earth's surface is the most important factor that can affect herbicide photodecomposition (Katagi, 2004). This can be biologically harmful, but on the other hand, decomposition of environmental pollutants, including herbicides, has a positive effect. Various factors can affect herbicide photodecomposition, including the sunlight intensity (dependent on the season and weather conditions), characteristics of the application site (such as latitude, altitude etc.), the application method, the characteristics of the herbicide, formulation and adjuvants added to their formulations or applied as tank mix to herbicide spray solution (Fred, 1997).

Many studies dealt with photodecomposition of sethoxydim (Shoaf and Carlson, 1986; Sevila moran et al. 2010), alloxydim (Sevilamoran et al., 2008), clethodim (Falb et al., 1990), atrazine (Sun et al., 2011), imazamox (Quivet et al., 2006), bentazon, clopyralid and triclopyr (Eyheraguibel et al., 2009), HW-02 (Lu et al., 2010), tribenuron-methyl (Bhattacharjeel and Dureja, 2002), acifluorfen (Vulliet, 2001), MCPA (Zertal et al., 2005), EPTC (Abu-Qare and Duncan, 2002), norflurazon (Massad et al., 2004), sulcotrione (Wiszniowski et al., 2009), fluometuron (Halladja et al., 2007), all conducted in water solution. However, herbicide reactivity on leaves' surface at different light is seldom evaluated. Moreover, the effect of adjuvants is rarely considered. 
Commercial formulations of some herbicides, such as sulcotrione, include different neutral materials, including adjuvants, due to which photodecomposition occurs faster than in the case of pure active ingredient (Wiszniowski et al., 2009). Adjuvants are important tools used to improve physical aspects of herbicide application and/or to enhance their biological efficacy, therefore are present in majority of herbicide formulations (Rashed-Mohassel et al., 2009; $2010 ; 2011)$. Along with the adjuvants, penetration agents, by increasing the rate of herbicide entrance and absorption into leafs, can influence photodecomposition (Devendra $e t$ $a l, 2004)$. Vegetable derived oils are one of the main groups of penetration agents (Ramsey et al., 2005). Harrison and Wax (1985) reported that vegetable oil can enhance photodecomposition of 2,4-D bentazon and holoxyfop herbicides when released. Therefore, the use of vegetable oils can reduce photodecomposition on leaf surface (increase herbicide penetration into leaf) and enhance photodecomposition in the environment. As little information about the effect of adjuvants on herbicide photostability on leaf surface exists, this study aimed to evaluate the effect of applying vegetable oils on sethoxydim and analyze its performance under simulated light on wild oat (Avena ludoviciana L.).

\section{Material and methods}

\section{Plant growth}

About $500 \mathrm{~g}$ wild oat caryopsis fruit were collected from the fields near the Greenhouse of College of Agriculture, Ferdowsi University of Mashhad, Iran, and preserved in a refrigerator (at $4 \pm 1^{\circ} \mathrm{C}$ ). To break seed dormancy, the caryopsis fruit were dehulled and seeds placed in $11 \mathrm{~cm}$ diameter Petri dishes over the surface of a single layer of Whatman no. 1 filter paper. Ten $\mathrm{ml}$ of $\mathrm{KNO}_{3}$ solution $(2 \mathrm{~g}$ $\left.\mathrm{L}^{-1}\right)$ were added to each Petri dish, two times. Petri dishes were placed in a refrigerator at $4-5^{\circ} \mathrm{C}$ in the dark for two days and then transferred to an incubator with $20 / 10^{\circ} \mathrm{C}$ temperature in $45 / 65 \%$ relative humidity, for a $16 / 8 \mathrm{~h}$ day/night for germination. As soon as the rootlets emerged from the seeds, they were sown in $2 \mathrm{~L}$ plastic pots that were filled with a mixture of sand, silty loam soil (19.8\% sand, $20.1 \%$ clay, $58 \%$ silt, $4.1 \%$ organic matter and a $\mathrm{pH}$ of 6.7 ) and peat $(1: 1: 1 ; \mathrm{v} / \mathrm{v} / \mathrm{v})$ at a $0.5 \mathrm{~cm}$ depth. The pots were irrigated every three days with tap water. The seedlings were thinned to five per pot at the two leaf stage and $40 \mathrm{~mL}$ of a water-soluble N:P:K (20:20:20) fertilizer, at a concentration of $3 \mathrm{~g}$ of fertilizer per liter of tap water, were supplied to each pot. The greenhouse temperature varied from $24 \pm 3^{\circ} \mathrm{C}$ during the day and $16 \pm 2{ }^{\circ} \mathrm{C}$ at night.

\section{Extraction of the vegetable oils}

Oils of soybean, cottonseed, canola, sesame, castor, corn, sunflower and turnip were extracted from grains via mechanical extraction method (Kemper, 2005), while olive oil was extracted from fruits with Decanter centrifugation (horizontal centrifuge rotating $3.000 \mathrm{rpm}$ ) method (Rubio, 2008).

\section{Fatty acid content detection}

To determine the fatty acid of the oils, fifteen drops of each vegetable oil were added to $7 \mathrm{ml} \mathrm{N}$-hexane, plus $2 \mathrm{ml}$ of potassium hydroxide in methanol $(11.2 \% \mathrm{~m} / \mathrm{v})$. Four replications of these compounds were shacked for $1 \mathrm{~min}$ and heated to $55^{\circ} \mathrm{C}$ for $5 \mathrm{~min}$, when the solution separated in two-phases. The upper phase were desiccated with sodium lauryl sulfate and filtered for analyzing with gas chromatography (Mehmood et al., 2008).

The fatty acid content was determined using specialized gas chromatography equipped with a flame ionization detector and a CP-Sil 88 Wcot fused silica column $(100 \mathrm{~m}$ $\times 0.25 \mathrm{~mm}$ i.d. $\times 0.2 \mu \mathrm{m}$ film thickness). The carrier gas was ultra-high purity helium (1:100 split mode) and a flameionization detector. The GC oven temperature was maintained at $140{ }^{\circ} \mathrm{C}$ for five min, then ramped to $240{ }^{\circ} \mathrm{C}$ at $4{ }^{\circ} \mathrm{C} / \mathrm{min}$ and kept at $240{ }^{\circ} \mathrm{C}$ for $15 \mathrm{~min}$. Flow rate of helium was $20 \mathrm{ml} / \mathrm{min}$. The injector and detector temperatures were 250 and $280{ }^{\circ} \mathrm{C}$, respectively. The volume of injected sample was $1 \mu l$. Fatty acids were identified by matching their retention times with those of their relative standards. The reference standards of fatty acid methyl esters in methylene chloride (ampule containing 10 $\mathrm{mg} / \mathrm{ml}$ ) was purchased (grain fatty acid methyl ester mix 99-100\%).

\section{Dose-response study}

The experiment was arranged in a randomized complete factorial design with four replications and carried out in a greenhouse at the Faculty of Agriculture, Ferdowsi University of Mashhad, Iran, in 2013. Wild oat plants were sprayed with herbicide at the four-leaf stage. Sethoxydim treatment consisted of seven doses against wild oat $(0,23.4$, $46.8,93.7,187.5,281.2$ and $375 \mathrm{~g}$ ai ha $\left.^{-1}\right)$. A non-ionic emulsifier and $100 \%$ alkylarylpolyglycol were added to each vegetable oil at $10 \%(\mathrm{v} / \mathrm{v})$. This compound $(90 \%$ vegetable oil $+10 \%$ emulsifier) was added to the sethoxydim solution at $0.5 \%(\mathrm{v} / \mathrm{v})$ in tank mix, for all treatments- with or without simulated light. Simulated light was applied at 5 , $10,20,30,60,120$ and $240 \mathrm{~min}$ after spraying (MAS), for a $30 \mathrm{~min}$ period, by using a light simulator that was supplied with a xenon arc lamp (1500 W) equipped with two ventilator fans; no light treatment was used as control. Treatments were applied using an overhead trolley sprayer equipped by 8002 flat fan nozzle tip, delivering 238 L ha-1 at $200 \mathrm{kPa}$. Four weeks after spraying, above-ground biomass of all the plants in each pot were harvested and weighed (fresh weigh), then oven dried at $75^{\circ} \mathrm{C}$ for $48 \mathrm{~h}$ and reweighed (dry weigh). This experiment was repeated twice and gave similar results. Hence, the results of one of the two will be reported.

\section{Statistical analyses}

Since fresh weight and dry weight data showed similar trend, only $E D_{50}$ dose based on dry weight data was included. Weight data of all the treatments were subjected to non-linear regression analyses by using a logistic doseresponse model (Ritz et al., 2006):

$$
U=C+\frac{D-C}{1+\exp \left[b\left(\log (z)-\log \left(E D_{50}\right)\right)\right]}
$$

where, $U$ is the plant response to the herbicide treatment, $z$ is the dose, $D$ and $C$ are the upper and lower limits of the curve respectively. $E D_{50}$ denotes the required dose of herbicide to give $50 \%$ wild oat control and $b$ is proportional to the slope of the curve around the $E D_{50}$. 
462

The logistic response-dose model was fitted to the experimental data by the $\mathrm{R}$ software and then based on available information the relative potency $(R P)$ value was used to describe horizontal displacement between the doseresponse curves:

$$
R P=E D_{50 \text { sethoxy dim }} / E D_{50 x}
$$

where, $E D_{50 x}$ is the $E D_{50}$ of sethoxydim alone or in combination with (i) vegetable oils and (ii) vegetable oils plus simulated light.

If the RP-value was equal to 1 , the addition of vegetable oils and the application of light treatment would not have any effect on herbicidal responses. While if the RP-value was bigger or smaller than 1 , herbicide usage with treatments would be more or less potent than herbicide alone (Ritz et al., 2006).

\section{Results and discussion}

\section{Vegetable oils effect on sethoxydim performance}

The results from this research showed that when sethoxydim was combined with each vegetable oil, wild oat control was remarkably increased. The $E D_{50}$ values of sethoxydim were significantly decreased (Tab. 1) and the $\mathrm{RP}$-value was considerably increased when each vegetable oil were added to sethoxydim (Tab. 2). These results indicate an increase in the performance of sethoxydim. The performance of sethoxydim in the presence of turnip, olive, soybean, corn, sunflower, canola, sesame, castor and cottonseed oils, compared to non-vegetable oil treatment, increased up to 4.02-, 3.44-, 3.22-, 3.08-, 2.86-, 2.09-, 1.96-, 1.77 - and 1.25 - fold respectively (Tab. 2). Therefore, turnip and cottonseed oil had the highest and the lowest efficiency when they were added to sethoxydim solution. Increasing the foliar activity of sethoxydim, quizalofop, fluazifop, fenoxaprop and haloxyfop in grassy weeds and bentazone, acifluorfen, lactofen, fomesafen and imazaquin in broadleaf weeds as a result of vegetable oils has been reported by Nalewaja (1994). This action may be due to increasing retention, penetration on cuticular wax and dissolve process in cuticule (Hazen, 2000; Ramsey et al., 2005).

\section{Effect of light on sethoxydim with vegetable oils on leaf surface}

Simulated light increased remarkably the $E D_{50}$ values of sethoxydim (Tab. 1) and the RP-value was considerably decreased when simulated light happened immediately after spraying sethoxydim (Tab. 1). When simulated light treatment was applied at 5, 10,20, 30, 60, 120 and 240 MAS, the $E D_{50}$ values of sethoxydim increased from 111.76 (without oil) to $995.23,927.24,804.94,632.27,214.38$, 111.88 and $112.25 \mathrm{~g}$ ai ha ${ }^{-1}$, respectively. Namely, for obtaining the same performance with no light treatment we must apply sethoxydim solution by 8.91-, 8.29-, 7.20-, 5.66-, $1.92-$, 1.01-, 1.00- fold, respectively. Increasing the interval time between sethoxydim spray and light treatment led to a decrease photodecomposition from the surface of leaves, due to increased penetration of sethoxydim on leaves' cuticule, and eventually a decrease of the adverse effect of light in sethoxydim performance, as when light happen at 120 and 240 MAS adverse effect of light is very low (Tab. 1). In general, increasing herbicide penetration on cuticular wax and dissolving cuticule are the main reasons for enhancement of resistance to light in the presence of vegetable oils (Hazen, 2000; Ramsey et al., 2005; Devendra et al, 2004).

Tab. 1.ED 50 dose ( $\mathrm{g}$ ai ha ${ }^{-1}$ ) of sethoxydim (alone and in a mixture with vegetable oils), affected by different light treatments

\begin{tabular}{|c|c|c|c|c|c|c|c|c|}
\hline & No Light & $\begin{array}{c}\text { Light at } 5 \\
\text { MAS }\end{array}$ & $\begin{array}{l}\text { Light at } 10 \\
\text { MAS }\end{array}$ & $\begin{array}{l}\text { Light at } 20 \\
\text { MAS }\end{array}$ & $\begin{array}{c}\text { Light at } 30 \\
\text { MAS }\end{array}$ & $\begin{array}{c}\text { Light at } 60 \\
\text { MAS }\end{array}$ & $\begin{array}{c}\text { Light at } 120 \\
\text { MAS }\end{array}$ & $\begin{array}{c}\text { Light at } 240 \\
\text { MAS }\end{array}$ \\
\hline Novegetable oil & $111.76(7.04)$ & $995.23(48.36)$ & $927.24(45.73)$ & $804.94(23.92)$ & $632.27(22.71)$ & $214.38(11.39)$ & $112.88(6.04)$ & $112.25(5.31)$ \\
\hline Turnip & $27.83(2.76)$ & $711.57(35.24)$ & $674.46(27.46)$ & $321.43(17.12)$ & $227.25(10.31)$ & $71.14(3.12)$ & $28.11(1.56)$ & $27.85(1.24)$ \\
\hline Olive & $32.46(2.91)$ & 721.75 (36.89) & $688.36(29.87)$ & $334.74(18.16)$ & $235.67(11.31)$ & $75.47(3.61)$ & $32.51(1.61)$ & $31.96(1.37)$ \\
\hline Soybean & $34.76(3.04)$ & $732.76(37.68)$ & $696.43(30.68)$ & $359.84(18.94)$ & $241.34(11.96)$ & $82.32(3.24)$ & $36.87(1.54)$ & $35.11(1.96)$ \\
\hline Corn & $36.27(3.29)$ & $743.57(38.56)$ & $704.76(31.17)$ & $377.57(19.21)$ & $249.71(12.73)$ & $85.87(4.27)$ & $38.86(2.24)$ & $37.49(2.11)$ \\
\hline Sunflower & $38.96(3.74)$ & $747.74(38.63)$ & $710.13(34.67)$ & $387.67(20.04)$ & $284.41(13.07)$ & $87.69(5.09)$ & $41.22(2.54)$ & $40.81(2.25)$ \\
\hline Canola & $53.42(3.86)$ & $790.24(39.22)$ & $732.39(37.46)$ & $414.68(21.14)$ & $345.37(14.39)$ & $110.31(6.35)$ & $53.74(3.02)$ & $53.08(2.95)$ \\
\hline Sesame & $57.15(3.97)$ & $794.64(39.54)$ & $751.18(38.13)$ & $443.97(22.07)$ & $357.81(16.64)$ & $114.54(6.76)$ & $57.89(3.18)$ & $56.01(3.74)$ \\
\hline Castor & $63.27(4.37)$ & $801.28(41.92)$ & $772.72(39.24)$ & $478.37(24.78)$ & $381.24(18.21)$ & $127.25(7.26)$ & $62.74(3.96)$ & $62.03(3.24)$ \\
\hline Cottonseed & $89.43(5.33)$ & $823.97(44.62)$ & $786.57(40.89)$ & $501.57(25.41)$ & $431.34(21.48)$ & $162.24(8.84)$ & $93.91(4.44)$ & $90.96(4.38)$ \\
\hline
\end{tabular}

Standard errors are in parentheses $(\mathrm{P}=0.05)$. MAS- minutes after spraying

Tab. 2. Relative potency of sethoxydim (alone and in a mixture with vegetable oils) affected by light treatments

\begin{tabular}{|c|c|c|c|c|c|c|c|c|}
\hline & No Light & $\begin{array}{c}\text { Light at } 5 \\
\text { MAS }\end{array}$ & $\begin{array}{c}\text { Light at } 10 \\
\text { MAS }\end{array}$ & $\begin{array}{c}\text { Light at } 20 \\
\text { MAS }\end{array}$ & $\begin{array}{c}\text { Light at } 30 \\
\text { MAS }\end{array}$ & Light at $60 \mathrm{MAS}$ & $\begin{array}{c}\text { Light at } 120 \\
\text { MAS }\end{array}$ & $\begin{array}{c}\text { Light at } 240 \\
\text { MAS }\end{array}$ \\
\hline No vegetable oil & 1 & 1 & 1 & 1 & 1 & 1 & 1 & 1 \\
\hline Turnip & $4.02(0.36)$ & $1.40(0.07)$ & $1.38(0.05)$ & $2.50(0.13)$ & $2.78(0.12)$ & $3.01(0.13)$ & $4.01(0.21)$ & $4.03(0.17)$ \\
\hline Olive & $3.44(0.28)$ & $1.38(0.08)$ & $1.35(0.06)$ & $2.40(0.12)$ & $2.68(0.12)$ & $2.84(0.13)$ & $3.47(0.16)$ & $3.51(0.14)$ \\
\hline Soybean & $3.22(0.26)$ & $1.36(0.07)$ & $1.33(0.07)$ & $2.24(0.11)$ & $2.50(0.13)$ & $2.60(0.10)$ & $3.06(0.12)$ & $3.20(0.17)$ \\
\hline Corn & $3.08(0.26)$ & $1.34(0.07)$ & $1.32(0.06)$ & $2.13(0.10)$ & $2.41(0.10)$ & $2.50(0.11)$ & $2.90(0.16)$ & $2.99(0.16)$ \\
\hline Sunflower & $2.86(0.25)$ & $1.33(0.06)$ & $1.31(0.05)$ & $2.08(0.10)$ & $2.13(0.07)$ & $2.44(0.13)$ & $2.74(0.16)$ & $2.75(0.14)$ \\
\hline Canola & $2.09(0.14)$ & $1.26(0.06)$ & $1.27(0.06)$ & $1.94(0.09)$ & $1.76(0.08)$ & $1.94(0.11)$ & $2.10(0.11)$ & $2.11(0.11)$ \\
\hline Sesame & $1.96(0.13)$ & $1.25(0.06)$ & $1.23(0.06)$ & $1.81(0.08)$ & $1.69(0.08)$ & $1.87(0.10)$ & $1.95(0.10)$ & $2.00(0.13)$ \\
\hline Castor & $1.77(0.11)$ & $1.24(0.05)$ & $1.20(0.05)$ & $1.68(0.08)$ & $1.58(0.07)$ & $1.68(0.09)$ & $1.80(0.11)$ & $1.81(0.09)$ \\
\hline Cottonseed & $1.25(0.07)$ & $1.21(0.04)$ & $1.18(0.05)$ & $1.60(0.07)$ & $1.40(0.06)$ & $1.32(0.06)$ & $1.20(0.06)$ & $1.23(0.06)$ \\
\hline
\end{tabular}

Standard errors are in parentheses $(\mathrm{P}=0.05)$

MAS- minutes after spraying 
Effect of vegetable oil composition on the photodecompositon sethoxydim on leafsurface

Vegetable oils' compositions are summarized in Tab. 3. Fatty acids of vegetable oils may affect the solubilizing, softening or disrupting of the cuticular waxes (Hazen, 2000). Therefore, fatty acids composition may affect the herbicide photodecomposition on leaf surface. The type of saturate or unsaturate fatty acids constitutive of vegetable oil affect the sethoxydim performance (Tab. 3). Similar results have been reported by Izadi-Darbandi et al. (2013). The results from this study revealed that fatty acids from vegetable oils had effect on sethoxydim photodecomposition on leaf surface, as with increasing unsaturated fatty acid values, the photodecomposition decreased and therefore the performance of sethoxydim on wild oat increased (Fig.1). A positive relationship exist between relative potency and unsaturated fatty acid values, as with increasing unsaturated fatty acid values, relative potency increased in various light treatment. To test the significance of the correlation coefficients (Snedecor and Cochran, 1989) correlation coefficients were used. This test showed significant differences between correlation coefficients. A negative relationship exist between linoleic fatty acid values and relative potency, as with increasing linoleic fatty acid values, relative potency decreased in various light treatment (Tabs. 2 and 3).

Tab. 3. Fatty acid composition of vegetable oils

\begin{tabular}{|c|c|c|c|c|c|c|c|c|c|c|c|c|c|}
\hline \multirow[t]{2}{*}{ Source } & \multicolumn{5}{|c|}{ Saturates } & \multicolumn{5}{|c|}{ Mono- Unsaturates } & \multicolumn{2}{|c|}{ Poly-Unsaturates } & \multirow[t]{2}{*}{$\begin{array}{c}\text { Unsat/Sat } \\
\text { ratio }\end{array}$} \\
\hline & $16: 0$ & 18:0 & $20: 0$ & $22: 0$ & $24: 0$ & $16: 1$ & $18: 1$ & $20: 1$ & $22: 1$ & $24: 1$ & $18: 2$ & $18: 3$ & \\
\hline Turnip & 3.85 & 1.13 & 0.75 & 1.01 & 0.56 & 0.27 & 15.38 & 9.34 & 43.99 & 2.19 & 8.96 & 10.65 & 12.4 \\
\hline Soybean & 5.63 & 3.26 & 0.83 & 0.49 & 0.14 & 0.14 & 54.11 & 1.68 & 0.67 & - & 25.75 & 7.3 & 8.66 \\
\hline Cottonseed & 20.87 & 3.19 & 0.37 & - & - & 0.55 & 20.1 & - & - & - & 53.78 & 0.21 & 2.94 \\
\hline Sunflower & 6.54 & 3.92 & 0.32 & 1.13 & 0.50 & 0.26 & 51.68 & 0.32 & - & - & 35.23 & - & 6.99 \\
\hline Olive & 7.1 & 2.05 & 0.24 & - & - & 0.5 & 69.84 & 0.14 & - & - & 19.85 & - & 9.64 \\
\hline Castor & 9.54 & 10.52 & 0.92 & - & - & - & 34.05 & 2.73 & - & - & 37.94 & 4.29 & 3.76 \\
\hline Sesame & 9.90 & 5.95 & 0.82 & 0.22 & 0.07 & 0.20 & 40.55 & 0.29 & - & - & 41.19 & 0.54 & 4.83 \\
\hline Corn & 4.92 & 2.95 & 0.91 & 0.52 & 0.22 & 0.25 & 60.54 & 2.15 & - & 0.26 & 18.41 & 8.04 & 8.66 \\
\hline Canola & 12.32 & 2.49 & 0.75 & 0.20 & 0.37 & 0.14 & 30.89 & 0.29 & - & - & 50.70 & 0.86 & 4.84 \\
\hline
\end{tabular}

Percentages may not add to $100 \%$ due to rounding and other constituents not listed

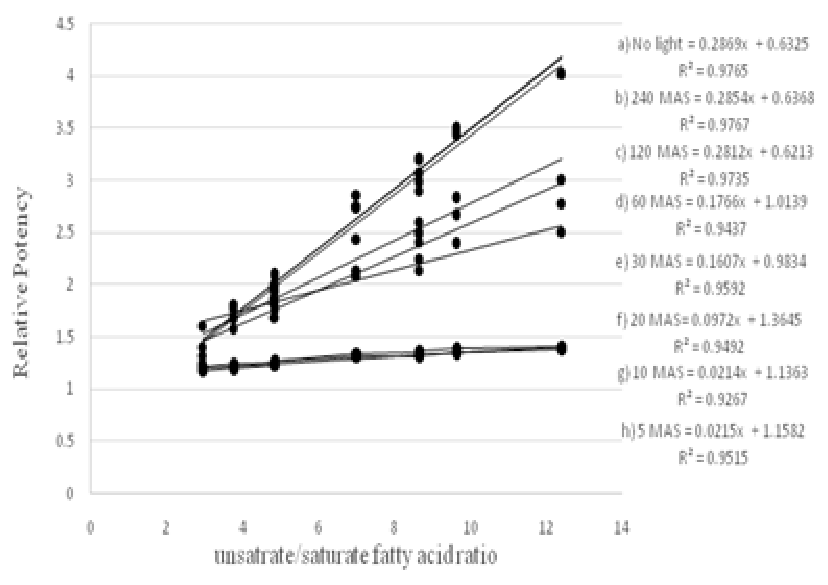

Fig. 1. Relationship between relative potency of sethoxydim (alone and in a mixture with vegetable oils), in light treatments and unsatrate/saturate fatty acid ratio

\section{Conclusion}

Based on the results of this study, the following conclusions can be made: (i) by using vegetable oils the performance of sethoxydim has been highly improved comparing with control (no vegetable oil); (ii) vegetable oils can be ranked based on relative potency value to turnip $>$ olive $>$ soybean $>$ corn $>$ sunflower $>$ canola $>$ sesame $>$ castor > cottonseed; (iii) based on their ability to enhance the efficacy of sethoxydim under the simulated light condition, the rank is turnip $>$ olive $>$ soybean $>$ corn $>$ sunflower $>$ canola $>$ sesame $>$ castor $>$ cottonseed; (iv) when light treatment was applied at 120 and 240 MAS, it did not decrease sethoxydim performance.

\section{References}

Abu-Qare AW, Duncan HJ (2002). Photodecomposition of the herbicide EPTC and the safener dichlormid, alone and in combination. Chemosphere 46:1183-1189.

Bhattacharjeel AK, Dureja P (2002). Light- induced transformation of tribenuron-methyl on glass, soil and plant surface. J Environ Sci Health, Part B 37:131-140.

Devendra R, Umamahesh V, Prasad TVR, Prasad TG, Asha ST, Shok A (2004). Influence of surfactants on efficacy of different herbicides in control of Cyperus rotundus and Oxalis latifolia. Current Sci 86:1148-1151.

Eyheraguibel B, Ter-halle A, Richard C (2009). Photodecomposition of Bentazon, Clopyralid, and Triclopyr on Model Leaves: Importance of a Systematic Evaluation of Pesticide Photostability on Crops. J Agric Food Chem 57:19601966.

Falb LN, Bridges DC, Smith AE (1990). Effects of $\mathrm{pH}$ and adjuvants on clethodim photodecomposition. J Agric Food Chem 38:875-878.

Fred F (1997). Pesticides and the environment, p. 1-6. In: Agricultural M U Guide. University Extension, University of Missouri-Columbia.

Halladja S, Amine-Khodja A, Halle A, Boulkamh A, Richard C (2007). Photolysis of fluometuron in the presence of natural water constituents. Chemosphere 69:1647-1654.

Harrison SK, Wax LM (1985). The effect of adjuvants and oil carriers on photodecomposition of 2, 4-D, bentazon and haloxyfop. Weed Sci 34:81-87.

Hazen JL (2000). Adjuvants: terminology, classification, and chemistry. Weed Technol 14:773-784. 
464

Izadi-Darbandi E, Aliverdi A, Hammami H (2013). Behavior of vegetable oils in relation to their influence on herbicides' effectiveness. Ind Crop Prod 44:712-717.

Katagi T (2004). Photodegradation of Pesticides on Plant and Soil Surfaces. Rev Environ Contam Toxicol 182:1-195.

Kemper TG (2005). Industrial Oil and Fat Products. Oil Extraction. Sixth Edition, John Wiley and Sons, Inc.

Lu Z, Hou Z, Wang X, Wang S, Shang Y, Yuan X (2010). Photodecomposition of new herbicide HW-02 in organic solvents. J Environ Sci 22:1774-1778.

Massad W, Criado S, Bertolotti S, Pajares A, Gianotti J, Escalada JP, Amat-Guerri F, Garcia NA (2004). Photodecomposition of the herbicide Norflurazon sensitized by Riboflavin. A kinetic and mechanistic study. Chemosphere 57:455-461.

Mehmood S, Orhan I, Ahsan Z, Aslan S, Gulfraz M (2008). Fatty acid composition of seed oil of different Sorghum bicolor varieties. Food Chem 109:855-859.

Nalewaja JD (1994). Esterified seed oil adjuvants. Proceedings of the forty ninth annual meeting of the North Central Weed Science Society, Grand Rapids, Michigan, USA, 13-15 December 1994: 149-156.

Quivet E, Faure R, Georges J, Pai-ssea JO, Herbreteau B, Lanteri J (2006). Photochemical Degradation of Imazamox in Aqueous Solution: Influence of Metal Ions and Anionic Species on the Ultraviolet Photolysis. J Agric Food Chem 54:3641-3645.

Ramsey RJL, Stephenson GR, Hall JC (2005). A review of the effects of humidity, humectants, and surfactant composition on the absorption and efficacy of highly water-soluble herbicides. Pesticide Biochem and Physiol 82:162-175.

Rashed-Mohassel MH, Aliverdi A, Ghorbani R (2009). Effects of a magnetic field and adjuvant in the efficacy of cycloxydim and clodinafop-propargyl on the control of wild oat (Avena fatua). Weed Biol Manage 9:300-306.

Rashed-Mohassel MH, Aliverdi A, Hammami H, Zand E (2010). Optimizing the performance of diclofop-methyl, cycloxydim, and clodinafop-propargyl on littleseed canarygrass (Phalaris minor) and wild oat (Avena ludoviciana) control with adjuvants. Weed Biol Manage 10:57-63.
Rashed-Mohassel MH, Aliverdi A, Rahimi S (2011) Optimizing dosage of sethoxydim and fenoxaprop-p-ethyl with adjuvants to control wild oat. Ind Crop Prod 34:1583-1587.

Ritz C, Cedergreen N, Jensen JE Streibig JC (2006). Relative Potency in Nonsimilar Dose-response Curves. Weed Sci 54:407-412.

Rubio JC (2008). Olive Oil History and Facts. Aceites Toledo SA. Pp 20.

Schnoor JL (1991). Fate of Pesticides and Chemicals in the Environment. Wiley- Interscience, New York.

Sevilla-Morána B, Mateo-Mirandaa MM, Alonso-Pradosa JL, García-Baudína JM, Sandín-Españaa P (2010). Sunlight transformation of sethoxydim-lithium in natural waters and effect of humic acids. Inter J Environ Analy Chem 90:487-496.

Sevilla-Moran B, SandinEspañaa P, Vicente-Arana MJ, AlonsoPrados JL, Garcia-Baudina JM (2008). Study of alloxydim photodecomposition in the presence of natural substances: Elucidation of transformation products. J Photochem Photobiol A 198:162-168.

Shoaf AR, Carlson WC (1986). Analytical techniques to measure sethoxydim and breakdown products. Weed Sci 34:745-751.

Snedecor GW, Cochran WG (1989) Statistical methods ( $8^{\text {th }}$ ed). The Iowa State University Press, U.S.A.

Sun X, Liu H, Zhang Y, Zhao Y, Quan X (2011). Effect of Cu (II) and humic acid on atrazine photodecomposition. J Environ Sci 23:773-777.

Vulliet E, Emmelin C, Scrano L, Bufo SA, Chovelon JM, Meallier P, Grenier-Loustalot MF (2001). Photochemical Degradation of Acifluorfen in Aqueous Solution. J Agric Food Chem 49:47954800.

Wiszniowski J, Ter Halle A, Richard C, Hitmi A, Ledoigt G (2009). Photodecomposition product of sulcotrione and the physiological response of maize (Zea mays) and white mustard (Sinapis alba). Chemosphere 74:1224-1230.

Zertal A, Jacquet M, Lavedrine B, Sehili T (2005). Photodecomposition of chlorinated pesticides dispersed on sand. Chemosphere 58:1431-1437. 